\title{
Effect of short-term water deficit stress on antioxidative systems in cucumber seedling roots
}

\author{
Huai-Fu Fan ${ }^{1,2+}$, Ling Ding ${ }^{1+}$, Chang-Xia Du ${ }^{1,2^{*}}$ and Xue $\mathrm{Wu}^{1}$
}

\begin{abstract}
Background: Cucumber is one of the most popular vegetables, and have little tolerance for water stress. The antioxidant defense system is one of major drought defense and adaptive mechanisms in plants, however, relatively few data are available regarding antioxidant systems in responses of cucumber to water deficit. The effect of short-term drought stress on the antioxidant system, lipid peroxidation and water content in cucumber seedlings roots was investigated.

Results: The results showed that polyethylene glycol (PEG) induced water stress markedly decreased water content of cucumber seedling roots after treatment of $36 \mathrm{~h}$, and caused excessive generation of reactive oxygen species (ROS) including superoxide $\left(\mathrm{O}_{2}^{-}\right)$, hydrogen peroxide $\left(\mathrm{H}_{2} \mathrm{O}_{2}\right)$. Meanwhile, malondialdehyde (MDA) content increased. Antioxidant enzymes including superoxide dismutases (SOD), peroxidases (POD), catalase (CAT) and ascorbate peroxidase (APX) activities increased in different time and different extent under water stress, while ascorbate (AsA) and glutathione (GSH) content, glutathione reductase (GR), dehydroascorbate reductase (DHAR) and monodehydroascorbate reductase (MDHAR) activities all decreased when compared to control.

Conclusions: Therefore, it can be concluded that water stress strongly disrupted the normal metabolism of roots and restrained water absorption, and seemingly enzymatic system played more important roles in protecting cucumber seedling roots against oxidative damage than non-enzymatic system in short-term water deficit stress.
\end{abstract}

Keywords: Cucumis sativus; Antioxidative enzymes; Antioxidants; Reactive oxygen species; Drought stress

\section{Background}

Water deficit is a major environmental factor restricting plant growth, development and productivity, particularly in arid regions more than any other single environmental factor. It seems the worldwide losses in crop yields from water deficit probably exceed the cumulative loss of all other stresses (Kramer 1983). Seasonal drought is becoming a severe challenge in agriculture production in the Yangtze River Basin in China. It usually happens from June to August when is critical time for most crops, even worse, it tends to come along with high temperature (Huang et al. 2013). It is well known that drought stress impairs numerous metabolic and physiological processes in plants (Mahajan and Tuteja 2005).

\footnotetext{
* Correspondence: changxiadu@zafu.edu.cn

${ }^{\dagger}$ Equal contributors

'School of Agriculture and Food Science, Zhejiang Agriculture \& Forestry University, Lin'an, Zhejiang 311300, China

${ }^{2}$ The Key Laboratory for Quality Improvement of Agricultural Products of Zhejiang Province, Zhejiang Agriculture \& Forestry University, Lin'an, Zhejiang 311300, China
}

\section{Springer}

(c) 2014 Fan et al.; licensee Springer. This is an Open Access article distributed under the terms of the Creative Commons Attribution License (http://creativecommons.org/licenses/by/4.0), which permits unrestricted use, distribution, and reproduction in any medium, provided the original work is properly credited. tential and relative water content (RWC) and directly affects many aspects of plant physiology (Correia et al. 2006). Drought could induce excessive generation of reactive oxygen species (ROS) including superoxide anion $\left(\mathrm{O}_{2}{ }^{-}\right)$, hydrogen peroxide $\left(\mathrm{H}_{2} \mathrm{O}_{2}\right)$ and hydroxyl radical $\left(\mathrm{HO}^{-}\right)$, which could cause deterioration of membrane lipids, proteins and nucleic acids, leading to increased membrane leakage of solutes (Huang et al. 2013; Shehab et al. 2010). Thus, oxidative stress is one of the major causes of cellular damage in plants during stress (Miller et al. 2010). However, to remove ROS and maintain redox homeostasis, plants have evolved a complex array of antioxidant defense systems to prevent oxidative injury resulting from high levels of ROS, which includes antioxidative enzymes superoxide dismutases (SOD), peroxidases (POD), catalase (CAT), glutathione reductase (GR) and ascorbate peroxidase (APX), dehydroascorbate reductase (DHAR), and monodehydroascorbate reductase (MDHAR) (Asada 2006), low molecular mass 
antioxidants ascorbate (AsA), glutathione (GSH), and some compatible solutes such as betaines and proline (Foyer and Noctor 2005; Veljovic-Jovanovic et al. 2006). Previous studies have shown that drought tolerant cultivars generally have enhanced constitutive antioxidant enzyme activity under drought stress in comparison with sensitive cultivars (Sun et al. 2013). Maintaining a higher level of antioxidative enzyme activities may contribute to drought induction by increasing the capacity against oxidative damage (Sharma and Dubey 2005).

Cucumber is one of the most popular vegetables, and it is considered a shallow-rooted crop and has been reported to have little tolerance for water stress. The antioxidant defense system is one of major drought defense and adaptive mechanisms in plants (An and Liang 2013). To the best of our knowledge, however, relatively few data are available regarding antioxidant systems in responses of cucumber to water deficit. Therefore, in the present study, we investigated the effect of water deficit on antioxidant systems of cucumber seedlings.

\section{Methods}

\section{Plant material and treatments}

The experiments were carried out in the environmentcontrolled greenhouse. Cucumber (Cucumis sativus L., cv. Jinyou No. 1) seeds were placed in sterile Petri plates on filter paper moistened with distilled water. They were allowed to germinate in the dark in a thermostaticallycontrolled chamber at $29 \pm 1^{\circ} \mathrm{C}$ for approximately $30 \mathrm{~h}$. The germinated seeds were sown in 50 cells plug trays containing peat moss and perlite $(1: 1, \mathrm{v} / \mathrm{v})$ at $1200 \mu \mathrm{mol} \mathrm{m}{ }^{-2} \mathrm{~s}^{-1}$ photosynthetic photo flux density and $14 / 10$ h $\left(25-30 / 16-20^{\circ} \mathrm{C}\right)$ day/night regime. Relative humidity fluctuated between 60 and 75\%. At the two-leaf stage, seedlings were removed from the plastic plates, and the roots were rinsed with distilled water. Uniformly sized healthy seedlings were selected and transferred into troughs $(40 \times 30 \times 13 \mathrm{~cm})$ filled with $10 \mathrm{~L}$ of full-strength Hoagland's nutrient solution, which was aerated for $40 \mathrm{~min}$ each hour. After pre-culturing for $3 \mathrm{~d}$, the seedlings were treated with the following methods: (1) control [CK (full-strength Hoagland's nutrient solution)]; (2) 5\% polyethylene glycol 6000 (PEG) treatment [5\% PEG (full-strength Hoagland's nutrient solution containing 5\% PEG)]; (3) 10\% PEG treatment [10\% PEG (full-strength Hoagland's nutrient solution containing 10\% PEG)]; each treatment has nine containers, and each container includes 6 plants, providing a total of 54 plants per treatment. Root samples of CK and 10\% PEG treatment were harvested in triplicate at $0,12,24$ and $36 \mathrm{~h}$ after the treatment initiation and immediately frozen in liquid nitrogen, and stored at $-80^{\circ} \mathrm{C}$ for the subsequent analyses. After $36 \mathrm{~h}$ of treatment, plant roots per treatment were collected for the determination of water content (WC).

\section{Determination of WC of root}

Roots of cucumber seedlings were washed with tap water two to three times, rinsed twice with distilled water, gently blotted dry with a paper towel, and weighed for fresh weight. Oven dried at $70^{\circ} \mathrm{C}$ to constant dry weight. WC of roots was calculated according to the formula $\mathrm{WC}=$ [(Fresh weight-dry weight)/ Fresh weight] $\times 100 \%$.

\section{Enzyme extraction and assays}

For the enzyme assays, $0.3 \mathrm{~g}$ roots were ground with $2 \mathrm{~mL}$ ice-cold $25 \mathrm{mM}$ HEPES buffer ( $\mathrm{pH}$ 7.8) containing $0.2 \mathrm{mM}$ EDTA, $2 \mathrm{mM}$ ascorbate and $2 \%$ PVP. The homogenates were centrifuged at $4^{\circ} \mathrm{C}$ for $20 \mathrm{~min}$ at $12,000 \times g$ and the supernatant was used for enzyme activity assay. All steps in the preparation of the enzyme extract were carried out at $4^{\circ} \mathrm{C}$. SOD activity assay was based on the method described by Giannopotitis and Ries (1977). POD activity was measured using modification of the procedure of Egley et al. (1983) , the reaction mixture in a total volume of $2 \mathrm{~mL}$ contained $25 \mathrm{mM}$ ( $\mathrm{pH} 7.0$ ) sodium phosphate buffer, $0.1 \mathrm{mM}$ EDTA, $0.05 \%$

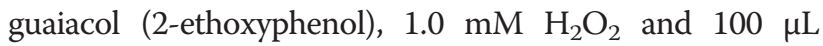
enzymes extract. The increase of absorbance due to oxidation of guaiacol was measured at $470 \mathrm{~nm}$. APX activity was determined according to Nakano and Asada (1981). CAT activity was done according to Cakmak and Marschner (1992). GR activity was measured as a decrease in $A_{340}$ due to oxidation of NADPH according to Foyer and Halliwell (1976). MDHAR activity was determined following Hossain et al. (1984) with slight modification. The reaction mixture contained $50 \mathrm{mM}$ of Tris- $\mathrm{HCl}$ buffer ( $\mathrm{pH}$ 7.5), $1 \mathrm{mM}$ of $\mathrm{NADH}, 5 \mathrm{mM}$ of ascorbic acid, $0.15 \mathrm{U}$ of ascorbate oxidase and $30 \mu \mathrm{L}$ of

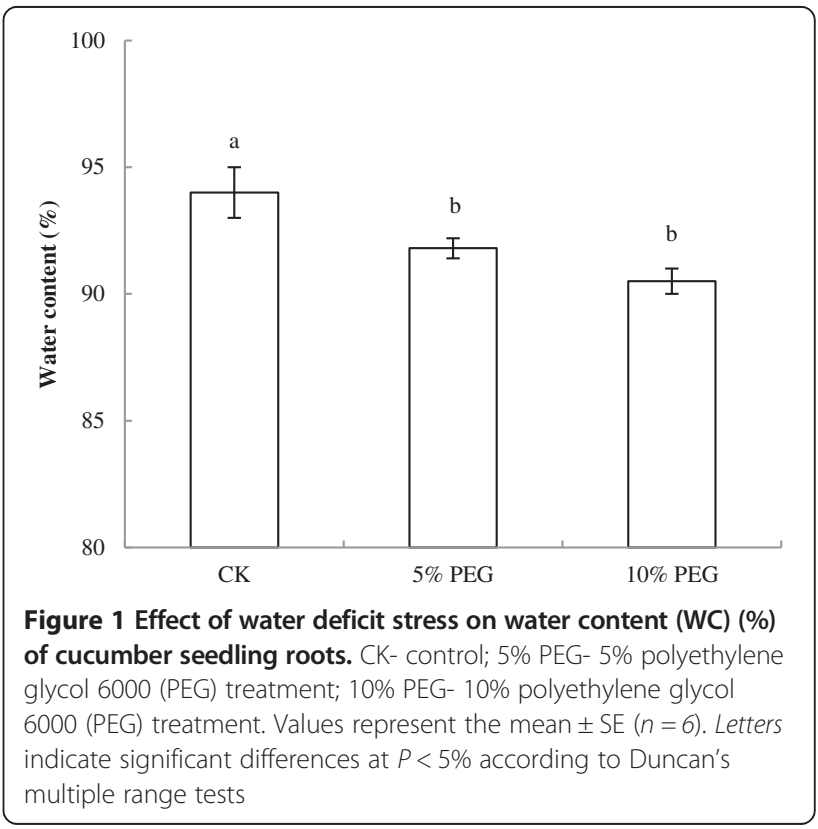


enzymes extract. The activity was calculated from the change in absorbance at $A_{340}$ for 2 min when the extinction coefficient was $6.2 \mathrm{mM}^{-1} \mathrm{~cm}^{-1}$. DHAR activity was determined following Nakano and Asada (1981) with some modifications. The reaction mixture contained $50 \mathrm{mM}$ of $\mathrm{KH}_{2} \mathrm{PO}_{4}$ buffer (pH 7.0), $50 \mathrm{mM}$ of $\mathrm{GSH}$, $10 \mathrm{mM}$ of DHA and $50 \mu \mathrm{L}$ of enzyme extract. The activity was calculated from the change in absorbance at $A_{265}$ for $2 \mathrm{~min}$ when the extinction coefficient was $14 \mathrm{mM}^{-1} \mathrm{~cm}^{-1}$.

\section{Determination of free radical production}

The $\mathrm{O}_{2}^{-}$production rate was measured according to Elstner and Heupel (1976) by monitoring the nitrite formation from hydroxylamine in the presence of $\mathrm{O}_{2}{ }^{-{ }^{-}}$, with some modifications. One $g$ root segments was homogenized with $3 \mathrm{~mL}$ of $65 \mathrm{mM}$ phosphate buffer ( $\mathrm{pH} 7.8$ ), $0.1 \mathrm{~mL}$ of $10 \mathrm{mM}$ hydroxylamine hydrochloride, and
$1 \mathrm{~mL}$ supernatant. After incubation at $25^{\circ} \mathrm{C}$ for $20 \mathrm{~min}$, ethyl ether in the same volume was added and centrifuged at $1,500 \times g$ for $5 \mathrm{~min}$. A standard curve with $\mathrm{NO}_{2}^{-}$was used to calculate the production rate of $\mathrm{O}_{2}{ }^{-}$from the chemical reaction of $\mathrm{O}_{2}^{-}$and hydroxylamine. $\mathrm{H}_{2} \mathrm{O}_{2}$ content was measured by the titanium method (Patterson et al. 1984). MDA content was measured by the thiobarbituric acid reaction method (Heath and Packer 1968).

\section{Assay of antioxidants}

AsA content was measured in extracts according to the method of Jiang and Zhang (2001). GSH content was determined as described by Griffith (1980).

\section{Statistical analysis}

All data presented are the mean values. All experiments were conducted using three replicates at least. All data were statistically analyzed by the analysis of variance

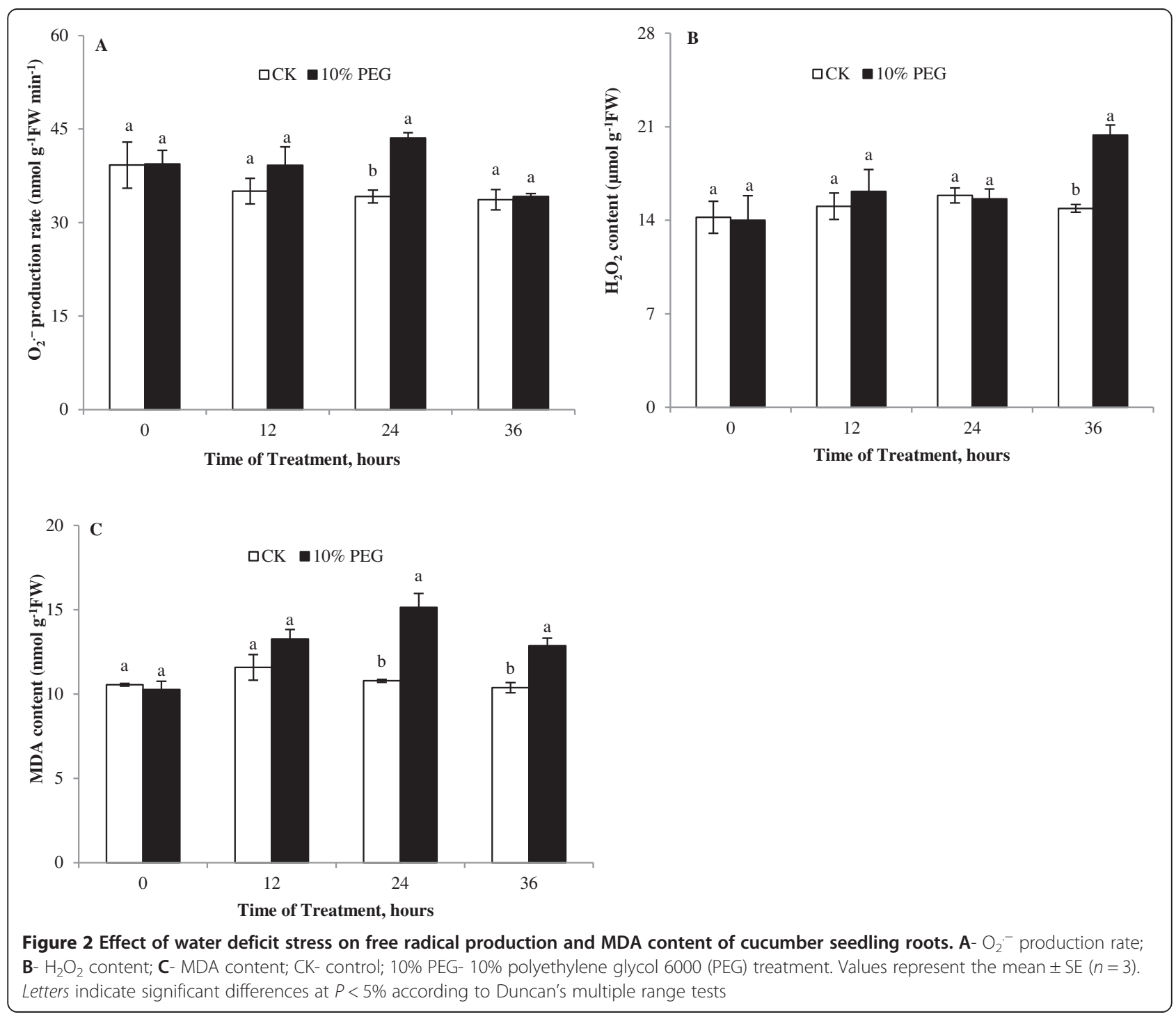



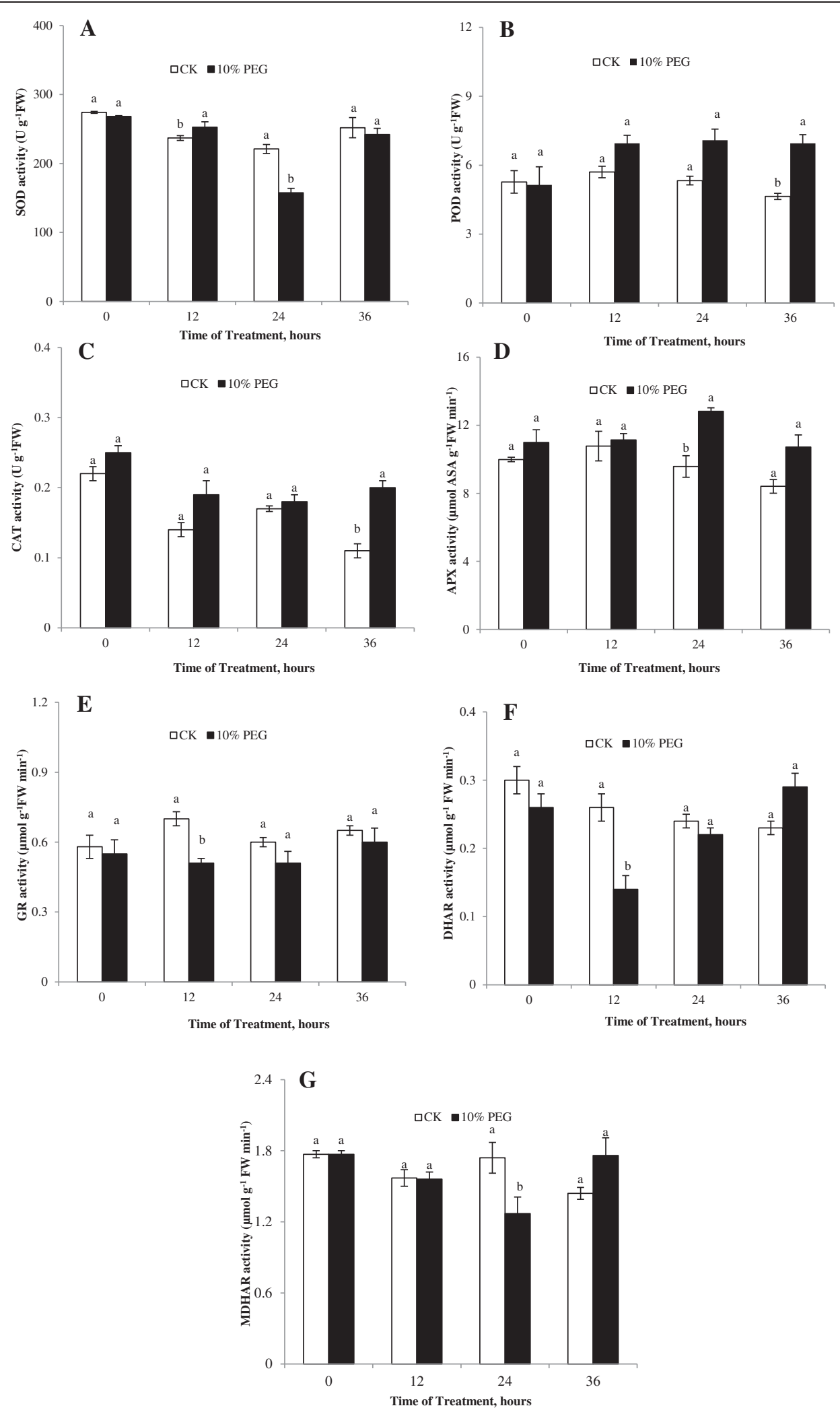

Figure 3 Effect of water deficit stress on enzyme activity of cucumber seedling roots. A- SOD activity; B- POD activity; C- CAT activity; D- APX activity; E- GR activity; F- DHAR activity; G- MDHAR activity; CK- control; 10\% PEG- 10\% polyethylene glycol 6000 (PEG) treatment. Values represent the mean $\pm \mathrm{SE}(n=3)$. Letters indicate significant differences at $P<5 \%$ according to Duncan's multiple range tests. 
(ANOVA) with SAS software (SAS Institute, Cary, United States) using Duncan's multiple range test at the 0.05 level of significance.

\section{Results and discussions}

Water state and oxidative free radical production in the roots of cucumber seedlings subjected to a short term water stress

Drought stress reduces leaf size, stem extension and root proliferation, disturbs plant water relations and reduces water-use efficiency (Farooq et al. 2009). In the present investigation, leaves of cucumber showed severely wilted appearance after $36 \mathrm{~h}$ under PEG treatment, and WC of roots was decreased dramatically (Figure 1 ).

Generation of ROS are common events during drought (Farooq et al. 2009). Among ROS, $\mathrm{H}_{2} \mathrm{O}_{2}$, as a more stable ROS, can diffuse across biological membranes and severely damages plant metabolism under stress conditions (Ashraf 2009). Here, the production rate of $\mathrm{O}_{2}{ }^{-}$and $\mathrm{H}_{2} \mathrm{O}_{2}$ content both increased in the cucumber roots under water stress, especially after $36 \mathrm{~h}$ (Figure 2A and B). Membrane injury is a consequence of lipid peroxidation. Increasing MDA content is a good reflection of oxidative damage to membrane lipids. In drought-stressed plants, the MDA content increased, and was significantly higher than in the non-drought controls after 24 or $36 \mathrm{~h}$ (Figure 2C), indicating that the membrane was damaged by ROS and pronounced cell membrane peroxidation occurred under PEG-induced stress.

The enzymatic antioxidation system in cucumber seedling roots in responses to a short term water stress

Antioxidative enzymes like SOD, POD and CAT play a significant role in conferring drought tolerance (Hameed et al. 2013). In this study, compared with control, SOD activity increased markedly in cucumber seedling roots exposed to water stress at $12 \mathrm{~h}$. An increase in SOD activity, which is commonly taken as an indicator of an increased ROS level. However, SOD activity was lower than the control after $24 \mathrm{~h}$ or $36 \mathrm{~h}$ and significant difference was found at $24 \mathrm{~h}$ of treatment (Figure 3A). The POD, CAT and APX activities exhibited increasing trends in response to drought stress (Figure 3B-3D). It is well known that APX and GR are the key enzymes participating in scavenging $\mathrm{H}_{2} \mathrm{O}_{2}$ within a cell via the Asada-Halliwell pathway (Foyer et al. 1994). During the whole treatment period, the GR activity was lower than control under stress and there was apparent difference between water stress and control at $24 \mathrm{~h}$, but thereafter no prominent decrease was observed after $36 \mathrm{~h}$ (Figure 3E). The promotion of antioxidant activity is probably a defense response. Nevertheless, as shown here and by others (Lee et al. 2009), these enzymes usually did not match the increasing ROS production under severe drought stress.

Responses of the non-enzymatic antioxidation systems in cucumber seedling roots to a short term water stress

The AsA-GSH cycle is one of the important protection systems against ROS in different cell compartments. Water stress led to a decrease of MDHAR activity within $24 \mathrm{~h}$ of treatment, but after $36 \mathrm{~h}$, MDHAR activity under water stress was apparently higher than the control. DHAR activity had the similar trend with MDHAR activity (Figure 3F and G). Meanwhile, ASA and GSH content decreased under water stress (Figure 4A and B), which was one of reasons of the ROS accumulation in roots. Niu et al. (2013) stated that the ASA - deficient $v t c 1$ mutants of Arabidopsis thaliana was more sensitive to drought stress than the wild
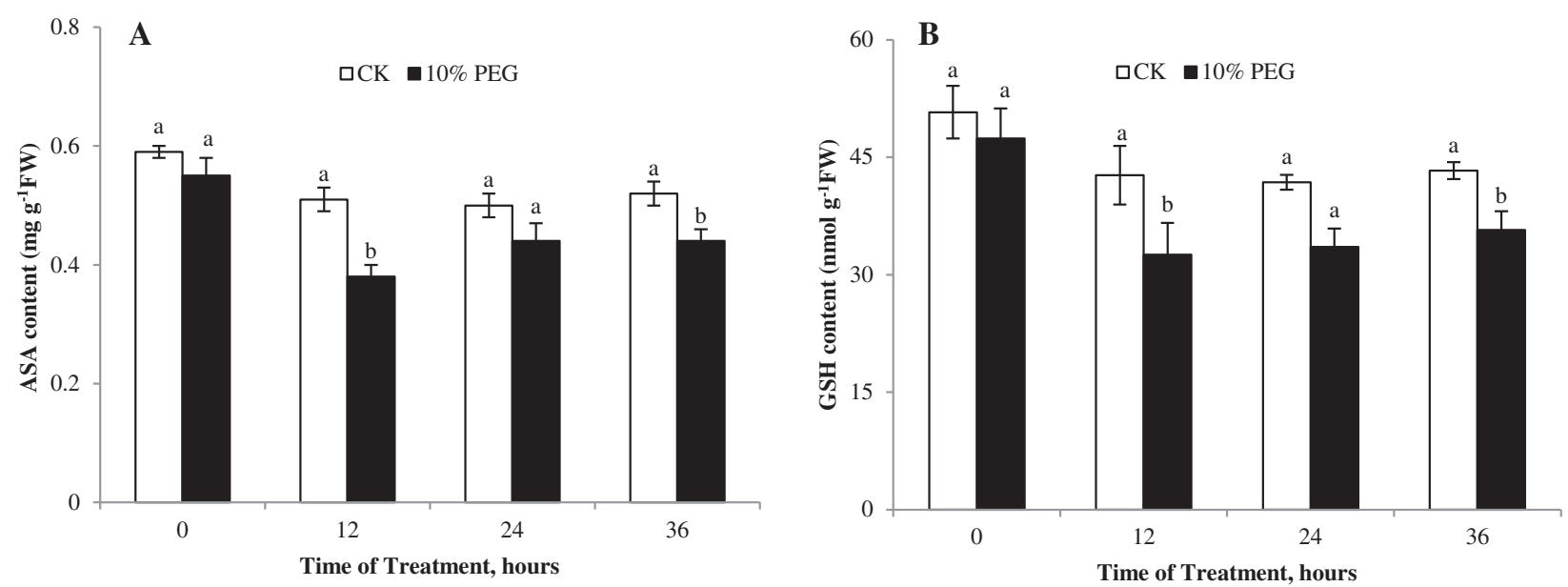

Figure 4 Effect of water deficit stress on antioxidants content of cucumber seedling roots. A- ASA content; B- GSH content; CK- control; 10\% PEG-10\% polyethylene glycol 6000 (PEG) treatment. Values represent the mean \pm SE $(n=3)$. Letters indicate significant differences at $P<5 \%$ according to Duncan's multiple range tests. 
- type. The low intrinsic ASA of the $v c t 1$ mutant decreased enzymatic antioxidant defense systems under drought stress. GR activity decreased was accompanied by a lower GSH content, suggesting that predominantly GSH oxidation took place under water stress. Similarly, drought induced oxidative stress in rice anthers leading to a PCD and pollen abortion along with down-regulation of antioxidants has been reported (Nguyen et al. 2009). The decrease in the ASA and GSH content can be connected with disturbances of ASA and GSH biosynthesis, such as the decrease of MDHAR and DHAR activities. It can also be related to their oxidation in ROS scavenging cycles.

\section{Conclusion}

In conclusion, the present results suggested that water deficit interrupted the ROS balance between generation and elimination in cucumber roots, which strongly disrupted the normal metabolism of roots and restrained the water absorption. Finally, plants become wilted and their stems did not stand upright. Interestingly, we also found that the enzymatic system (SOD, POD, CAT and APX), partially, enhanced the ROS-scavenging capacity to some extent in short-term water deficit stress, while nonenzymatic system (ASA and GSH) exhibited a relative decease of ROS-scavenging in this experiment. Seemingly it showed that the enzymatic system played more important roles in protecting cucumber seedling roots against oxidative damage than non-enzymatic system in short-term water deficit stress. However, extended studies are needed to understand a precise mechanism.

\section{Abbrevations \\ APX: Ascorbate peroxidase; AsA: Ascorbic acid; CAT: Catalase; \\ DHAR: Dehydroascorbate reductase; GR: Glutathione reductase; GSH: Reduced glutathione; $\mathrm{H}_{2} \mathrm{O}_{2}$ : Hydrogen peroxide; MDA: Malondialdehyde; MDHAR: Monodehydroascorbate reductase; $\mathrm{O}_{2}^{-{ }^{-}}$: Superoxide anion; POD: Peroxidase; ROS: Reactive oxygen species; SOD: Superoxide dismutase.}

\section{Competing interests}

The authors declare that they have no competing interests of this research.

\section{Authors'contributions}

LD and XW performed these experiments. HFF and CXD designed the research, analyzed data and wrote the paper. All the authors read and approved the final manuscript.

\section{Acknowledgements}

This research was supported by the National Natural Science Foundation of China (No. 31101539; No. 31201658).

Received: 18 March 2014 Accepted: 2 May 2014

Published: 23 May 2014

\section{References}

An YY, Liang ZS (2013) Drought tolerance of Periploca sepium during seed germination: antioxidant defense and compatible solutes accumulation. Acta Physiol Plant 35:959-967. doi:10.1007/ s11738-012-1139-z

Asada K (2006) Production and scavenging of reactive oxygen species in chloroplasts and their functions. Plant Physiol 141:391-396. doi:10.1104/pp. 106.082040
Ashraf M (2009) Biotechnological approach of improving plant salt tolerance using antioxidants as markers. Biotechnol Adv 27:84-93. doi:10.1016/j. biotechadv.2008.09.003

Cakmak I, Marschner H (1992) Magnesium deficiency and high light intensity enhance activities of superoxide dismutase, ascrobate peroxidase, and glutathione reductase in bean leaves. Plant Physiol 98:1222-1227. doi:10.1104/pp. 98.4.1222

Correia MJ, Osório ML, Osório J, Barrote I, Martins M, David MM (2006) Influence of transient shade periods on the effects of drought on photosynthesis, carbohydrate accumulation and lipid peroxidation in sunflower leaves. Environ Exp Bot 58:75-84. doi:10.1016/j. envexpbot. 2005. 06. 015

Egley GH, Paul RN, Vaughn KC, Duke SO (1983) Role of peroxidase in the development of water-impermeable seed coats in Sida spinosa L. Planta 157:224-232. doi:10.1007/BF00405186

Elstner EF, Heupel A (1976) Inhibition of nitrate formation from hydroxylammoniumchloride: a simple assay for superoxide dismutase. Anal Biochem 70:616-620. doi:10.1016/0003-2697(76)90488-7

Farooq M, Wahid A, Kobayashi N, Fujita D, Basra SMA (2009) Plant drought stress: effects, mechanisms and management. Agron Sustain Dev 29:185-212. doi:10.1007/ 978-90-481-2666-8_12

Foyer CH, Halliwell B (1976) The presence of glutathione and glutathione reductase in chloroplasts: a proposed role in ascorbic acid metabolism. Planta 133:21-25. doi:10.1007/BF00386001

Foyer CH, Lelandais M, Kunert KJ (1994) Photooxidative stress in plants. Physiol Plant 92:696-717. doi:10.1111/j.1399-3054.1994.tb03042.x

Foyer $\mathrm{CH}$, Noctor G (2005) Oxidant and antioxidant signalling in plants: a reevaluation of the concept of oxidative stress in a physiological context. Plant Cell Environ 28:1056-1071. doi:10.1111/ j. 1365-3040.2005.01327.x

Giannopotitis CN, Ries SK (1977) Superoxide dismutase in higher plants. Plant Physiol 59:309-314. doi:10.1104/pp. 59.2.309

Griffith OW (1980) Determination of glutathione and glutathione disulfide using glutathione reductase and 2-vinylpyridine. Anal Biochem 106:207-212. doi:10.1016/0003-2697(80)90139-6

Hameed A, Goher M, lqbal N (2013) Drought induced programmed cell death and associated changes in antioxidants, proteasea and lipid peroxidation in wheat leaves. Biol Plant 57:370-374. doi:10.1007/s10535-012-0286-9

Heath RL, Packer L (1968) Photoperoxidation in isolated chloroplasts. I. Kinetics and stoichiometry of fatty acid peroxidation. Arch Biochem Biophys 125:189-198. doi:10.1016/0003-9861(68)90654-1

Hossain MA, Nakano Y, Asada K (1984) Monodehydroascorbate reductase in spinach chloroplasts and its participation in the regeneration of ascorbate for scavenging hydrogen peroxide. Plant Cell Physiol 25:385-395

Huang CJ, Zhao SY, Wang LC, Anjum SA, Chen M, Zhou HF, Zou CM (2013) Alteration in chlorophyll fluorescence, lipid peroxidation and antioxidant enzymes activities in hybrid ramie (Boehmeria nivea L.) under drought stress. Aust J Crop Sci 7:594-599

Jiang MY, Zhang JH (2001) Effect of abscisic acid on active oxygen species, antioxidative defence system and oxidative damage in leaves of maize seedlings. Plant Cell Physiol 42:1265-1273. doi:10.1016/0003-9861(68)90654-1

Kramer PJ (1983) Plant Water Relations. Academic Press, New York

Lee BR, Li LS, Jung WJ, Jin YL, Avice JC, Ourry A, Kim TH (2009) Water deficitinduced oxidative stress and the activation of antioxidant enzymes in white clover leaves. Biol Plant 53:505-510. doi:10.1007/s10535-009-0091-2

Mahajan S, Tuteja N (2005) Cold, salinity and drought stresses: An overview. Arch Biochem Biophys 444:139-158. doi:10.1016/j.abb.2005.10.018

Miller G, Suzuki N, Ciftci-Yilmaz S, Mittler R (2010) Reactive oxygen species homeostasis and signaling during drought and salinity stresses. Plant Cell Environ 33:453-467. doi:10.1111/j.1365-3040.2009.02041.x

Nakano Y, Asada K (1981) Hydrogen peroxide scavenged by ascorbate-specific peroxidase in spinach chloroplasts. Plant Cell Physiol 22:867-880

Nguyen GN, Hailstones DL, Wilkes M, Sutton BG (2009) Drought-induced oxidative conditions in rice anthers leading to a programmed cell death and pollen abortion. J Agron Crop Sci 195:157-164. doi:10.1111/j.1439-037x. 2008.00357.x

Niu Y, Wang YP, Li P, Zhang F, Liu H, Zheng GC (2013) Drought stress induces oxidative stress and the defense system in ascorbate - deficient vct1 mutants of Arabidopsis thaliana. Acta Physiol Plant 35:1189-1200. doi:10.1007/s11738012-1158-9

Patterson BD, MacRae EA, Ferguson IB (1984) Estimation of hydrogen peroxide in plant extracts using titanium (IV). Anal Biochem 139:487-492. doi:10.1016 /0003-2697(84)90039-3 
Sharma P, Dubey RS (2005) Drought induces oxidative stress and enhances the activities of antioxidant enzymes in growing rice seedlings. Plant Growth Regul 46:209-221. doi:10.1007/ s10725- 005-0002-2

Shehab GG, Ahmed OK, El-beltagi HS (2010) Effects of various chemical agents for alleviation of drought stress in rice plants (Oryza sativa L.). Not Bot Hort Agrobot Cluj 38:139-148

Sun J, Gu J, Zeng J, Han S, Song AP, Chen FD, Fang WM, Jiang JF, Chen SM (2013) Changes in leaf morphology, antioxidant activity and photosynthesis capacity in two different drought-tolerant cultivars of chrysanthemum during and after water stress. Sci Hortic 161:249-258. doi:10.1016/j.scienta.2013.07.015

Veljovic-Jovanovic S, Kukavica B, Stevanovic B, Navari-Izzo F (2006) Senescence- and drought-related changes in peroxidase and superoxide dismutase isoforms in leaves of Ramonda serbica. J Exp Bot 57:1759-1768. doi:10.1093/jxb/erl007

doi:10.1186/s40529-014-0046-6

Cite this article as: Fan et al.: Effect of short-term water deficit stress on antioxidative systems in cucumber seedling roots. Botanical Studies 2014 55:46.

\section{Submit your manuscript to a SpringerOpen ${ }^{\circ}$} journal and benefit from:

- Convenient online submission

- Rigorous peer review

- Immediate publication on acceptance

- Open access: articles freely available online

- High visibility within the field

- Retaining the copyright to your article 